\title{
E-cigarette Aerosols Versus Cigarette Smoke: Harm Reduction in Levels of Harmful and Potentially Harmful Constituents and Cytotoxicity
}

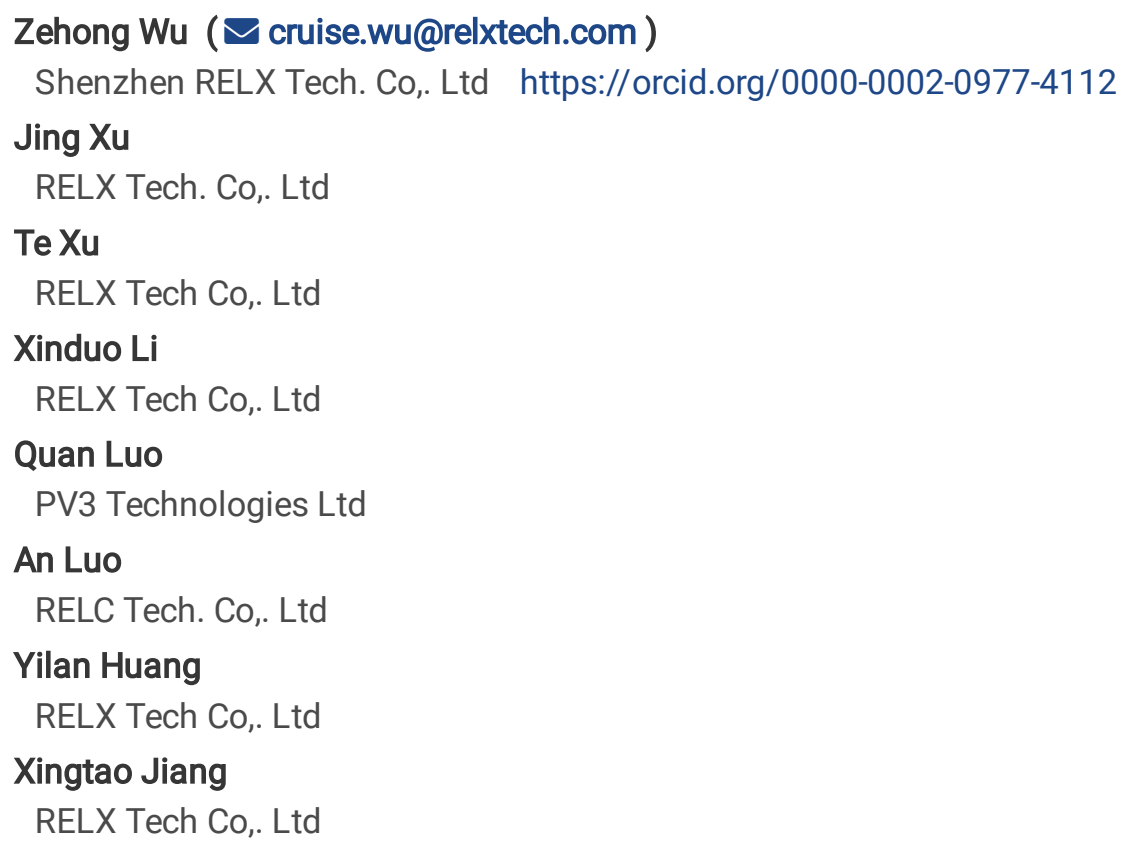

\section{Research}

Keywords: E-cigarette, aerosol, cigarette smoke (CS), harmful and potentially harmful constituents (HPHCs), total particulate matter (TPM), cytotoxicity

Posted Date: March 11th, 2021

DOI: https://doi.org/10.21203/rs.3.rs-288294/v1

License: (a) (i) This work is licensed under a Creative Commons Attribution 4.0 International License. Read Full License 


\section{Abstract}

Background: Worldwide adoption of electronic cigarettes (e-cigarettes) has increased exponentially over the past decade due to the perception that they may represent a safer alternative to conventional cigarettes (CS) and as an effort to reduce smokingrelated diseases. Various types of e-cigarettes from different brands have been emerged in the market with different design and quality. However, whether the safety risks of e-cigarettes held the trends toward positive changes need to be further certified by more scientific evidence.

Methods: A systematic comparison study on the selected harmful and potentially harmful constituents (HPHCs) levels, including carbonyls, volatile organic compounds (VOCs), tobacco-specific nitrosamines (TSNAs), polycyclic aromatic hydrocarbons (PAHs), and metals in aerosols of two typical commercially available e-cigarettes and one cigarette smoke (CS) in Chinese market were proceeded, together with their cytotoxicity on Jukart, CNE-1, HONE1, Hep-2 cell lines by CCK-8 and colony formation assays.

Results: The results showed that the levels of vast majority HPHCs in e-cigarette aerosols are either undetected or obviously lower than those in CS, which indicating the exposure to HPHCs was markedly reduced in the tested e-cigarettes. The CCK-8 and colony formation assay also indicated that the TPM extracts of e-cigarette aerosols also exhibited much weaker cytotoxicity than CS.

Conclusion: The comparison of HPHCs levels in e-cigarette aerosols revealed that the use of e-cigarettes could lead to a significant reduction in exposure to harmful substances compared to CS. In tandem, the potential cytotoxicity of e-cigarettes on cell levels also showed potential for improvement compared to smoking. However, more attention needs to be paid to the differences in safety risks between different brands of e-cigarettes.

\section{Introduction}

It is estimated that traditional cigarette smoking explains nearly $90 \%$ of lung cancer risk in men and $70-80 \%$ in women, and it is also responsible for almost 140000 premature deaths annually from cardiovascular disease (Biondi-Zoccai, et al. 2019). Despite the efforts to reduce smoking goes on for many years, the traditional smoking continues to be one of the most preventable risk factors for heart disease (Buchanan et al. 2020). The most important goal in decreasing the harmful effects of tobacco use should be the reduction or elimination of the use of combustible tobacco (Benowitz et al. 2017). Fortunately, the marketing of alternatives to combustible cigarettes and nicotine replacements have skyrocketed in recent years, such as electronic cigarettes (e-cigarettes) and heat-not-burn tobacco cigarettes. Especially for e-cigarettes, which have become more popular due to their efficiency in reducing tobacco consumption and the consumer perception of e-cigarette as a less harmful alternative to smoking since being introduced in 2006 (McNeill et al. 2015; Royal College of Physicians 2016).

The harmful and potentially harmful constituents (HPHCs) are chemicals or chemical compounds in tobacco products or tobacco smoke that cause or could cause harm to smokers or nonsmokers. FDA published a preliminary list of 93 HPHCs in March 2012, which mainly focuses on chemicals that are linked to the five most serious health effects of tobacco use (cancer, cardiovascular disease, respiratory effects, reproductive problems, and addiction). Thus, the HPHCs levels in tobacco products directly represent the levels of their safety risks to some extent. The main categories of these HPHCs include aldehydes and ketones (Carbonyls), volatile organic compounds (VOCs), tobacco-specific nitrosamines (TSNAs), polycyclic aromatic hydrocarbons (PAHs), and metals (Cheng et al. 2014; Belushkin et al. 2020).

E-cigarettes are the battery powered electronic devices that operate by using a heating element or atomizer that vaporizes a solution (e-liquid) without tobacco tar. The e-liquid, which may or may not contain nicotine, is mainly consisted of glycerol, propylene glycol (PG), and flavors with different spices, and functioning as cigarette substitutes for smoking cessation. During normal use, the e-cigarette devices operate at temperatures up to $\sim 250^{\circ} \mathrm{C}$, compared with $950^{\circ} \mathrm{C}$ peak temperatures reached in a burning cigarette (Nicol et al. 2020). The former research indicated that HPHCs in conventional cigarettes and cigarette smoke (CS) include more than 7000 items of which 69 are known carcinogens (Merecz-Sadowska et al. 2020). Thus, removal of these toxicants seems to be a feasible way to reduce the risk of disease. A comparable study found that the levels of 
selected carcinogens and toxicants in the smoke from a conventional cigarette were 9 450-fold higher than levels in the ecigarette aerosol (Goniewicz et al. 2014). Although e-cigarette is considered as a tool for harm reduction and smoking cessation (Caponnetto et al. 2011; Bullen et al. 2013), the technical index of different e-cigarette brands evolved significantly with wide variation in design, components, atomizing powers, and chemical constituents. The health effects of long-term vaping and especially for those nonsmokers who have just started using e-cigarette are also not clear. Therefore, the studies on the HPHCs and toxicological effects of e-cigarette aerosol emissions are essential to assess the potential health risks of these devices.

In order to assess the safety risks of representative e-cigarettes in the Chinese market, the selected HPHCs levels in aerosols of two typical commercially available e-cigarettes (RELX 0 with mung bean flavor, ECM and RELX 0 with tobacco flavor, ECT) and a CS in Chinese market were systematically analyzed. In addition, the potential cytotoxicity of the total particulate matter (TPM) extracts from ECM, ECT and CS on Jukart, CNE-1, HONE1, Hep-2 cell lines were also synchronously evaluated by CCK-8 and colony formation assays.

\section{Methods}

\section{E-cigarettes and Cigarettes}

The two tested flavored e-cigarettes (RELX 0 mung bean flavor with 3\% nicotine and RELX 0 tobacco flavor with $5 \%$ nicotine) are commercially available and were obtained from a RELX retail store with 6.5 watts fixed operating power. The e-cigarettes were stored at room temperature and the batteries were fully charged before use. The typical conventional cigarette was also sourced from a local retail location and stored in an air-tight container at room temperature until use.

\section{Sample Generation}

Cerulean CETI 8 MK3 (CERULEAN, UK) was used to generate e-cigarette aerosols and CS. All the e-cigarette aerosols and CS were generated according to the Cooperation Centre for Scientific Research Relative to Tobacco (CORESTA) Recommended Method No. 81 vaping regime which specifies a square-wave puff profile, $55 \mathrm{~mL}$ puff volume, $3 \mathrm{~s}$ duration and a $30 \mathrm{~s}$ interval (CORESTA 2015). The mainstream aerosol/smoke was passed through the collection vessels with special solvents for carbonyls, VOCs, and metals analysis or a 44-mm Cambridge filter pad for TSNAs, PAHs or total particulate matter (TPM) collection.

\section{Analysis of Carbonyls}

Carbonyl quantification tested was carried out based on the CORESTA Recommended Method No. 74 (CORESTA, 2019) and the standard of AFNOR XP D90-300-3 (AFNOR, 2016)] with some modifications. Both the mainstream e-cigarette aerosols and CS (100 puffs) produced by Cerulean CETI 8 MK3 were directly passed through the two collection vessels with $2 * 25 \mathrm{~mL}$ acetonitrile (1:10) (Supelco, US), and then derivatized with 2*10 mL of $0.02 \mathrm{M} \mathrm{DNPH} \mathrm{(Aladdin,} \mathrm{CN)} \mathrm{for} 25$ min to allow the formation of DNPH-adducts. The samples were then analyzed by an ultra-performance liquid chromatography (UPLC, Waters, US) coupled with a Waters UV detector (PDA e $\lambda$ ) and a Waters ACQUITY UPLC HSS T3 C18 column $(1.8 \mu \mathrm{m}, 2.1 * 100 \mathrm{~mm})$ for carbonyls chromatographic separation, with the gradient analysis (Table S2). Formaldehyde, acetaldehyde, acrolein, propionaldehyde, butenal, butyraldehyde, acetone, and butanone were identified in this study.

\section{Analysis of Volatile Organic Compounds (VOCs)}

The detection of VOCs, including 1,3-butadiene, isoprene, acrylonitrile, benzene, and methylbenzene, in e-cigarette aerosols and CS were based on the CORESTA Recommended Method No. 70 (COREST, 2018). Briefly, the VOCs were firstly collected by passing the mainstream aerosols/smoke (100 puffs) through two cryogenic traps containing $10 \mathrm{~mL}$ methanol. And then the two impinger solutions are fortified with $1 \mathrm{~mL}$ benzene-D6 (Aladdin, $\mathrm{CN}$ ) with the concentration of $400 \mathrm{ng} / \mathrm{mL}$ respectively and analyzed by GC-MS. GC-MS analysis was performed on an Agilent gas chromatograph, model GC-8860 system (Agilent, US), using a fused silica capillary column DB-624 (60m in length, $0.25 \mathrm{~mm}$ i.d., $0.25 \mathrm{~mm}$ i.d., and $1.40 \mu \mathrm{m}$ film thickness) (Agilent, US), and coupled with a mass spectrometer, model 5977B GC/MSD (Agilent, US). Helium gas (99.999\%) was used as the carrier gas at constant flow rate $1.2 \mathrm{~mL} / \mathrm{min}$, and an injection volume of $3 \mu \mathrm{L}$ was employed (split ratio of 30:1). The injector and ion- 
source temperatures were $150^{\circ} \mathrm{C}$ and $230^{\circ} \mathrm{C}$, respectively. The oven temperature was programmed from $40^{\circ} \mathrm{C}$ (isothermal for 6 min) with an increase of $20^{\circ} \mathrm{C} / \mathrm{min}$ to $225^{\circ} \mathrm{C} / \mathrm{min}$, ending with a $6 \mathrm{~min}$ isothermal at $225^{\circ} \mathrm{C}$.

\section{Analysis of Tobacco-specific Nitrosamines (TSNAs)}

An UPLC-MS/MS, model AcQuity $H$ (Waters, US), coupled with a Waters Xevo TQ-S micro detector and a Waters ACQUITY UPLC HSS T3 C18 column $(1.8 \mu \mathrm{m}, 2.1 * 100 \mathrm{~mm})$, was used to determine N-nitrosonornicotine (NNN), 4-(methylnitrosamino)-1-(3bipyridyl)-1-butanone (NNK), N-nitrosoanabasine (NAB), and N-nitrosoanatabine (NAT) in the aerosols and CS, based on the CORESTA Recommended Method No. 72 (CORESTA, 2017) with some modifications. Briefly, the TSNAs were firstly collected by passing the mainstream e-cigarette aerosols and CS (100 puffs) through a $44 \mathrm{~mm}$ Cambridge filter pad (Whatman ${ }^{\mathrm{TM}}$, UK), and then extracted by $20 \mathrm{~mL}$ acetonitrile/ammonium acetate $(100 \mathrm{mM})(50: 50 \mathrm{v} / \mathrm{v})$ mixture under shaking. After addition of deuterium labelled internal standards the sample is extracted into an aqueous buffer and filtered. All standards should be prepared in amber, or light protected glassware and stored in a freezer. The filtrate is analyzed by the UPLC-MS/MS (Table S5). The results are reported in units of nanograms per 100 puffs.

\section{Analysis of Polycyclic Aromatic Hydrocarbons (PAHs)}

PAHs, including naphthalene, acenaphthylene, acenaphthene, fluorene, phenanthrene, anthracene, fluoranthene, pyrene, chrysene, benz[a]anthracene, benzo[ $k]$ fluoranthene, benzo[ $b]$ fluoranthene, benzo[a]pyrene, indeno[1,2,3-c, $d]$ pyrene, dibenzo[ $a, h]$ anthracene, and benzo[ $g, h, i]$ perylene, were also tested on a Shimadzu gas chromatograph, model Nexis GC-2030 (SHIMADZU, Japan), using a fused silica capillary column HP-5MS UI (30 m in length, $0.25 \mathrm{~mm}$ i.d., $0.25 \mu \mathrm{m}$ film thickness) (Agilent, US), and coupled with a mass spectrometer, model QP-2020 NX (SHIMADZU, Japan), according to the PRC National Standard No. GB 5009.265-2016 (PCR-GB, 2016) with some modifications. The PAHs were also firstly collected by passing the mainstream aerosols/smoke (100 puffs) through a $44 \mathrm{~mm}$ Cambridge filter pad, and then extracted by $20 \mathrm{~mL}$ acetonitrile. Helium gas (99.999\%) was used as the carrier gas at constant flow rate $1.3 \mathrm{~mL} / \mathrm{min}$, and an injection volume of $3 \mu \mathrm{L}$ was employed. Injector temperature $280^{\circ} \mathrm{C}$; ion-source temperature $230^{\circ} \mathrm{C}$. The oven temperature was programmed from $120^{\circ} \mathrm{C}$ with an increase of $20^{\circ} \mathrm{C} / \mathrm{min}$ to $260^{\circ} \mathrm{C} / \mathrm{min}$, then $10^{\circ} \mathrm{C} / \mathrm{min}$ to $290^{\circ} \mathrm{C}$, ending with an 8 min isothermal at $290^{\circ} \mathrm{C}$.

\section{Analysis of Metals}

$\mathrm{Cr}, \mathrm{Ni}, \mathrm{As}, \mathrm{Cd}, \mathrm{Sb}, \mathrm{Pb}, \mathrm{Hg}, \mathrm{Al}, \mathrm{Mn}, \mathrm{Fe}, \mathrm{Co}, \mathrm{Cu}, \mathrm{Zn}$, Se, and $\mathrm{Sn}$ were analyzed using inductively coupled plasma mass spectrometry (ICP-MS), model ICP RQ (Thermo, US), according to the AFNOR XP D90-300-3 (AFNOR, 2016). The e-cigarette aerosols and CS generated by Cerulean CETI 8 MK3 were firstly collected by two series-wound dedicated collectors with $2 * 20 \mathrm{~mL} 2 \% \mathrm{HNO}_{3}$ in ultra-pure MilliQ water (Merck Millipore, US). The mixed solution of $10 \mu \mathrm{g} / \mathrm{L}{ }^{72} \mathrm{Ge},{ }^{115} \mathrm{In},{ }^{209} \mathrm{Bi}$ in ultra-pure MilliQ water was taken as the tuning solution. Five calibration standard solutions were prepared by dilution of high purity standards of $\mathrm{Cr}$, $\mathrm{Ni}$, As, $\mathrm{Cd}, \mathrm{Sb}, \mathrm{Pb}, \mathrm{Hg}, \mathrm{Al}, \mathrm{Mn}, \mathrm{Fe}, \mathrm{Co}, \mathrm{Cu}, \mathrm{Zn}$, Se, and Sn (100 $\mu \mathrm{g} / \mathrm{mL}$, National Nonferrous Metal and Electronic Materials Analysis and Testing Center, $\mathrm{CN}$ ). Calibration ranges for all metals spanned the observed levels in the aerosol digests. The ICP-MS was operated with standard 1,550 W RF power and $14 \mathrm{~L} / \mathrm{min}$ argon plasma gas. The carrier gas (sample gas) was optimized at 0.8 $\mathrm{L} / \mathrm{min}$. Typical optimized cell gas flow was $5.0 \mathrm{~mL} / \mathrm{min}$ helium. The atomizing chamber temperature was $2{ }^{\circ} \mathrm{C}$. The date was collected 3 points per peak with the skipping collection mode. Sampling depth was $10.0 \mathrm{~mm}$.

\section{Cell Cultures}

The cell lines of Jukart, CNE-1, HONE1, Hep-2 were provided by the Health Science Center of Shenzhen University, and were grown in DMEM supplemented with $10 \%$ fetal bovine serum. Cell culture was proceeded in constant temperature $\mathrm{CO}_{2}$ cell incubator MCO-15AC (SANYO, Japan). The sterile operation is carried out in the biosafety cabinet HR1500-区A2 (Haier, China). Material sterilization used MJ-series autoclaves (STIK, USA). The absorbance was determined by GENios enzyme marker (TECAN, Austria). Cell morphology was observed using the DM500 microscope (Leica, Germany).

\section{Cell Viability Assay}

The TPM on Cambridge filters was first extracted with unequal volume of DMSO (shaken for 30 minutes) to obtain the TPM extracts of ECM, ECT, and CS with the concentration of $50 \mathrm{mg} / \mathrm{mL}$. The assay was performed according to the method in the 
references by Cell Counting Kit-8 (Sigma, USA) (Deng et al., 2017; Li et al., 2018). Briefly, cells $\left(2 \times 10^{3} /\right.$ well) were seeded in the 96-well plate covered with $10 \%$ FBS-containing DMEM media and cultured overnight $\left(5 \% \mathrm{CO}_{2}, 37^{\circ} \mathrm{C}\right.$ for $\left.48 \mathrm{~h}\right)$. Various doses of TPM extracts (ECM, ECT and CS with $0.412,1.23,3.70,11.1,33.3$ and $100 \mu \mathrm{g} / \mathrm{mL}$ ) were incubated with cells with five parallel controls, phosphate buffer saline (PBS) (Gibco, USA) and DMSO served as the control and solvent control respectively. Cells were then treated with CCK-8 reagent (10 $\mu \mathrm{L}$ per well) for 3 hours in the incubator. Optical density was measured using a microplate reader (Thermo Scientific) in triplicate at wavelength $450 \mathrm{~nm}$ and the mean value of absorbance was referred to the quantity of viable cells. The cell viability was calculated as following:

cell viability $(\%)=\frac{O D \text { (experiment })-O D \text { (blank })}{O D \text { (control })-O D(\text { blank })} \times 100 \%$

The $\mathrm{IC}_{50}$ values were calculated using GraphPad Prism 8 (GraphPad Software, Inc.).

\section{Colony Formation Assay}

Colony formation assay is an in-vitro survival assay based on the ability of a single cell to grow into a colony (Li et al., 2018; Yu et al., 2018). The cells ( $10^{3} /$ well) were seeded in 6-well plates and cultured overnight to adhere to the plate. Cells were then treated with TPM extracts at different concentration or vehicle alone for 3 days. After treatment cells were cultured in $5 \% \mathrm{CO}_{2}$, $37^{\circ} \mathrm{C}$ for 14 days to allow colony formation. The colonies formed were stained with $1 \%$ crystal violet and photographed. The number of colonies were counted under the microscope. Data were obtained from 3 independent experiments, and percentage difference in colony formation compared with the control was then calculated.

\section{Results}

\section{Carbonyl Compounds}

The concentrations of formaldehyde, acetaldehyde, acrolein, propionaldehyde, butenal, butyraldehyde, acetone, and butanone in the e-cigarette aerosols and CS per 100 puffs were presented in table. As shown in Table 1, almost all of carbonyls in two ecigarette aerosols were at very low levels comparing with the limited values of AFNOR XP D90-300-3. On the contrary, the concentrations of most carbonyls in CS were also obviously higher than those in e-cigarette aerosols, especially for acrolein which was even 6-fold higher than the limited value. 
Table 1

The concentrations of carbonyls and VOCs in e-cigarette aerosols (ECT and ECM) and CS ( $\mu \mathrm{g} / 100 \mathrm{puffs}$ ).

\begin{tabular}{|c|c|c|c|c|c|c|c|}
\hline & Formaldehyde & Acetaldehyde & Acrolein & Propionaldehyde & Butenal & Butyraldehyde & Acetone \\
\hline $\begin{array}{l}\text { Limited } \\
\text { Value* }\end{array}$ & 200 & 3200 & 16 & NA & NA & NA & NA \\
\hline ECM & 1.7 & 1.7 & $<N D L$ & $<N D L$ & $<\mathrm{NDL}$ & $<N D L$ & 0.5 \\
\hline ECT & 2.6 & 4.2 & $<N D L$ & $<N D L$ & $<\mathrm{NDL}$ & $<\mathrm{NDL}$ & 1.0 \\
\hline \multirow[t]{2}{*}{$\mathrm{CS}$} & 18.9 & 1505.8 & 98.3 & 109.6 & ND & 85.5 & 521.6 \\
\hline & Butanone & $\begin{array}{l}1,3- \\
\text { Butadiene }\end{array}$ & Isoprene & Acrylonitrile & Benzene & \multicolumn{2}{|l|}{ Methylbenzene } \\
\hline $\begin{array}{l}\text { Limited } \\
\text { Value* }\end{array}$ & NA & NA & NA & NA & NA & \multicolumn{2}{|l|}{ NA } \\
\hline ECM & $<\mathrm{NDL}$ & $<\mathrm{NDL}$ & $<\mathrm{NDL}$ & $<N D L$ & $<\mathrm{NDL}$ & \multicolumn{2}{|l|}{$<\mathrm{NDL}$} \\
\hline ECT & 1.1 & $<\mathrm{NDL}$ & $<\mathrm{NDL}$ & $<N D L$ & $<\mathrm{NDL}$ & \multicolumn{2}{|l|}{$<\mathrm{NDL}$} \\
\hline $\mathrm{CS}$ & 131.0 & 1471.7 & 3419.6 & 10.2 & 185.0 & \multicolumn{2}{|l|}{110.4} \\
\hline \multicolumn{8}{|c|}{$\begin{array}{l}\text { Note: * means the limited values were based on AFNOR XP D90-300-3; NA means without limited value so far; The } \\
\text { conversion between cigarette and puff was } 10 \text { puffs per cigarette; The NDLs (no detection limits) of Acrolein, } \\
\text { Propionaldehyde, Butenal, Butyraldehyde, Butanone, 1,3-Butadiene, Isoprene, Acrylonitrile, Benzene, and Methylbenzene are } \\
0.66,0.60,0.18,0.36,0.45,5.08,31.03,8.91,6.88 \mu \mathrm{g} / 100 \text { puffs. }\end{array}$} \\
\hline
\end{tabular}

\section{Volatile Organic Compounds (VOCs)}

The concentrations of VOCs including 1,3-butadiene, acrylonitrile, isoprene, benzene, and methylbenzene in e-cigarette aerosols and CS were tested by an Agilent LC-MS, and the results were as shown in Table 1. VOCs in both two e-cigarette aerosols were no detected at current detection conditions, whereas were obviously high content in CS, especially for isoprene and 1,3butadiene.

\section{Tobacco-specific Nitrosamines (TSNAs)}

The concentrations of tobacco-specific nitrosamines (TSNAs), including NNN, NNK, NAB, and NAT in e-cigarette aerosols and CS were determined by an UPLC-MS/MS and as shown in Table 2. All the four TSNAs were no detected in the aerosols of ECT and ECM, however the concentrations of NNN, NAT, NAB in CS were tested as $117.6,508.2$, and $50.4 \mathrm{ng} / 100$ puffs respectively.

\section{Polycyclic Aromatic Hydrocarbons (PAHs)}

The PAHs of naphthalene, acenaphthylene, acenaphthene, fluorene, phenanthrene, anthracene, fluoranthene, pyrene, chrysene, benz[a]anthracene, benzo[ $k$ fluoranthene, benzo[ $b]$ fluoranthene, benzo[a]pyrene, indeno[1,2,3-c, $d]$ pyrene, dibenzo[ $a, h]$ anthracene, and benzo[ $g, h, i]$ perylene in e-cigarette aerosols (ECM and ECT) and CS were also tested by a Shimadzu GC-MS, and the results were as shown in Table 2. None of the sixteen PAHs were detected in ECT and ECM, whereas most of PAHs had been found in CS with the concentrations from 500 to $4000 \mathrm{ng} / 100$ puffs. 
Table 2

The concentrations of TSNAs and PAHs in e-cigarette aerosols (ECT, and ECM) and CS (ng/100 puffs).

\begin{tabular}{|c|c|c|c|c|c|}
\hline & NNN & NAT & NAB & NNK & Naphthalene \\
\hline ECM & $<N D L$ & $<\mathrm{NDL}$ & $<\mathrm{NDL}$ & $<\mathrm{NDL}$ & $<\mathrm{NDL}$ \\
\hline ECT & $<N D L$ & $<N D L$ & $<\mathrm{NDL}$ & $<\mathrm{NDL}$ & $<\mathrm{NDL}$ \\
\hline \multirow[t]{2}{*}{ CS } & 117.6 & 508.2 & 50.4 & $<N D L$ & $<N D L$ \\
\hline & Acenaphthylene & Acenaphthene & Fluorene & Phenanthrene & Anthracene \\
\hline ECM & $<N D L$ & $<N D L$ & $<N D L$ & $<\mathrm{NDL}$ & $<N D L$ \\
\hline ECT & $<N D L$ & $<\mathrm{NDL}$ & $<\mathrm{NDL}$ & $<\mathrm{NDL}$ & $<\mathrm{NDL}$ \\
\hline \multirow[t]{2}{*}{ CS } & 3989.9 & $<N D L$ & $<\mathrm{NDL}$ & 1609.2 & 578.5 \\
\hline & Fluoranthene & Pyrene & Chrysene & Benz[a]anthracene & Benzo[b]fluoranthene \\
\hline ECM & $<N D L$ & $<\mathrm{NDL}$ & $<\mathrm{NDL}$ & $<\mathrm{NDL}$ & $<\mathrm{NDL}$ \\
\hline ECT & $<N D L$ & $<N D L$ & $<N D L$ & $<N D L$ & $<N D L$ \\
\hline \multirow[t]{2}{*}{ CS } & 1213.4 & 1213.4 & 906.5 & 906.5 & 2093.7 \\
\hline & Benzo[k]fluoranthene & Benzo[a]pyrene & Indeno[1,2,3-c,d]pyrene & $\begin{array}{l}\text { Di- } \\
\text { benzo[a,h]anthracene }\end{array}$ & Benzo[g,h,i]perylene \\
\hline ECM & $<\mathrm{NDL}$ & $<\mathrm{NDL}$ & $<\mathrm{NDL}$ & $<\mathrm{NDL}$ & $<N D L$ \\
\hline ECT & $<N D L$ & $<\mathrm{NDL}$ & $<\mathrm{NDL}$ & $<\mathrm{NDL}$ & $<\mathrm{NDL}$ \\
\hline CS & 1308.6 & 905.7 & 779.1 & 764.0 & 647.2 \\
\hline
\end{tabular}

\section{Metals}

The analysis results of fifteen metals in the two e-cigarette aerosols (ECM and ECT) and CS were as shown in Table 3. Comparison with the ECT and ECM, the concentrations of $\mathrm{As}, \mathrm{Cd}, \mathrm{Sb}, \mathrm{Pb}, \mathrm{Fe}, \mathrm{Zn}$ and $\mathrm{Se}$ in CS are much higher than those in ecigarette aerosols, especially $\mathrm{Cd}$ with 4 -fold than the limit value. On the contrary, the concentrations of Ni in e-cigarette aerosols were $20 \sim 30$ times more than that in CS. 
Table 3

Metal concentrations in the e-cigarette aerosols (ECT, and ECM) and CS (ng/100 puffs).

\begin{tabular}{|c|c|c|c|c|c|c|c|c|c|}
\hline Metal & ECM & ECT & CS & Limited value* & Metal & ECM & ECT & CS & Limited value* \\
\hline $\mathrm{Cr}$ & 2.9 & 3.1 & 2.1 & 1,500 & $\mathrm{Mn}$ & $<\mathrm{NDL}$ & $<\mathrm{NDL}$ & 3.6 & NA \\
\hline $\mathrm{Ni}$ & 104 & 63 & 3.2 & 2,500 & $\mathrm{Fe}$ & $<N D L$ & $<N D L$ & 88 & NA \\
\hline As & 1.6 & 2.0 & 67 & 1,000 & Co & 0.04 & 0.02 & 0.2 & NA \\
\hline $\mathrm{Cd}$ & 0.01 & 0.04 & 974 & 1,000 & $\mathrm{Cu}$ & 13 & 2.2 & 32 & NA \\
\hline $\mathrm{Sb}$ & 0.1 & 0.07 & 30 & 10,000 & $\mathrm{Zn}$ & 133 & 120 & 820 & NA \\
\hline $\mathrm{Pb}$ & 5.2 & 7.8 & 388 & 2,500 & $\mathrm{Se}$ & $<\mathrm{NDL}$ & 0.2 & 12 & NA \\
\hline $\mathrm{Hg}$ & 1.5 & 2.5 & 1.7 & NA & Sn & 11 & 0.1 & 0.7 & NA \\
\hline $\mathrm{Al}$ & 118 & 40 & 211 & \multicolumn{6}{|l|}{ NA } \\
\hline \multicolumn{10}{|c|}{$\begin{array}{l}\text { Note: } \mathrm{Cr} \text {, chromium; Ni, nickel; } \mathrm{As} \text {, arsenic; } \mathrm{Cd} \text {, cadmium; } \mathrm{Sb} \text {, antimony; } \mathrm{Pb} \text {, lead; } \mathrm{Hg} \text {, mercury; Al, aluminum; Mn, manganese; } \\
\text { Fe, iron; Co, cobalt; Cu, copper; Zn zinc; Se, selenium; Sn, tin; * means the maximum permissible value for } 24 \text { hours (PDE) in } \\
\text { inhaled medication based on AFNOR XP D } 90-300-3 \text {; NA means no limited value temporally; The NDL (no detection limits) of } \\
\mathrm{Mn}, \mathrm{Fe} \text {, and Se were } 0.3,3.9 \text {, and } 0.03 \mathrm{ng} / 100 \text { puffs respectively. }\end{array}$} \\
\hline
\end{tabular}

\section{Effect of The TPM Extracts on Cell Viability}

The viabilities of four cell lines (Jukart, CNE-1, HONE1, Hep-2) were not be obvious inhibited in 48 hours after treated with the TPM extracts of two e-cigarette aerosols (ECM and ECT) at the tested dose ( $\left(\mathrm{C}_{50}>100 \mu \mathrm{g} / \mathrm{mL}\right.$, Fig. 1, 1A 1D). However, the TPM extract of CS exhibited potent cytotoxic on all of the four cell lines after processing 48 hours with the $\mathrm{IC}_{50}$ values of 85.04 , 56.21, 46.30, and $97.02 \mu \mathrm{g} / \mathrm{mL}$, respectively.

\section{Effect of the TPM Extracts on Cell Colony Formation}

The inhibition effect of the TPM extracts (ECM, ECT, and CS) on the cell colony formation were also further assessed.

Compared with normal controls, the 3-week treatment of $25 \mu \mathrm{g} / \mathrm{mL}$ TPM extract of CS sharply inhibited the colony formation on Jukart and Hep-2 cell lines, while the TPM extracts of ECM and ECT exhibited no obvious inhibition even at $100 \mu \mathrm{g} / \mathrm{mL}$ (Fig. 2$2 \mathrm{~A}$ and $2 \mathrm{D}$ ). Furthermore, the colony formation assay on CNE-1 and HONE1 cell lines showed that all the three TPM extracts exhibited various degrees of dose-dependently colony formation inhibition, whereas the inhibitory extent of ECT and ECM groups were obviously weaker than CS (Fig. 2-2B and 2C).

\section{Discussion}

Levels of carbonyl compounds in e-cigarette aerosols are mainly depends on the e-liquid solvent and battery output voltage. Both VG and PG could undergo decomposition at high temperatures to generate low molecular weight carbonyl compounds with established toxic properties, including formaldehyde, acetaldehyde, acrolein, and acetone (Kosmider et al., 2014). CS is the primary source of exposure to several VOC carcinogens and toxicants, whereas the VOCs in e-cigarette aerosols are rarely reported (Marco et al., 2015). TSNAs are the most prevalent strong carcinogens in smokeless tobacco products and CS, and widely believed to play a significant role as causes of oral cancer in people who use these products (Stepanov et al., 2005). PAHs are also a class of environmental pollutants created primarily from incomplete combustion of various organic materials including tobacco products, which is one significant source of PAHs exposure for smokers and secondhand smokers (Ding et al., 2005). The metals in CS are mainly from the pollution of the growing environment, processing and transportation process. The heating element of e-cigarettes is usually a metallic coil, which always contains Kanthal, made of iron, chromium, and aluminum, and Nichrome, made of nickel and chromium (Olmedo et al, 2018). Thus, the detection of these toxic metals such as chromium, nickel, and lead are very necessary for the risk monitoring of e-cigarettes. 
Public Health England reported that e-cigarettes were likely to be $95 \%$ less harmful than tobacco products and could be a means for smokers to quit or reduce their consumption of cigarettes (McNeill et al., 2015), based on the evidence of the composition and quantities of constituents found in e-cigarette aerosols and the relative risk associated with the main components. Although some studies have shown that a few adverse potential effects of e-cigarettes on cell models can be shown in vitro (Romagna et al., 2013; Humidah et al., 2018), and low levels of chronic irritation of the respiratory tract also can be anticipated at certain levels of vaping (Czekala et al., 2019), but the negative effects are much less than those of conventional cigarettes (Nutt et al., 2014).

In present study, the selected HPHCs in the two commercially available e-cigarette aerosols and a typically traditional CS from Chinese market were systematic comparatively tested, including eight carbonyls (formaldehyde, acetaldehyde, acrolein, propionaldehyde, butenal, butyraldehyde, acetone, and butanone), five VOCs (1,3-butadiene, acrylonitrile, isoprene, benzene, and methylbenzene), four TSNAs (NNN, NNK, NAB, and NAT), sixteen PAHs (naphthalene, acenaphthylene, acenaphthene, fluorene, phenanthrene, anthracene, fluoranthene, pyrene, chrysene, benz[a]anthracene, benzo[ $b]$ fluoranthene, benzo[ $k]$ fluoranthene, benzo[a]pyrene, indeno[1,2,3-c,d]pyrene, di-benzo[a, $h$ ]anthracene, and benzo[ $g, h$,$] perylene), and fifteen metal elements (Al, As,$ $\mathrm{Cd}, \mathrm{Cr}, \mathrm{Cu}, \mathrm{Fe}, \mathrm{Zn} \mathrm{Mn}, \mathrm{Ni}, \mathrm{Pb}, \mathrm{Sb}, \mathrm{Sn}, \mathrm{Hg}, \mathrm{Co}$, and $\mathrm{Se}$ ). A comparative study was also deduced to evaluate the toxicity of TPM extracts (ECM, ECT. and CS) by an in vitro model using one immune cell line Jukart, and three tumor cell lines (CNE-1, HONE1, Hep-2).

The carbonyls assaying indicated that the carbonyl compounds in aerosols of ECM and ECT were at the nanogram level per puff, which were far below the limited safety value. However, most of the toxic carbonyls in CS were at the microgram level (Table 1). None of the tested VOCs, TSNAs and PAHs had been detected in ECM and ECT aerosols at the current instrument detection limits, whereas most of the VOCs, TSNAs and PAHs in CS were at high levels (Tables 1-2). The concentrations of As, $\mathrm{Cd}, \mathrm{Sb}$, and $\mathrm{Pb}$ in $\mathrm{CS}$ were also much higher than those in e-cigarette aerosols, especially for $\mathrm{Cd}$ and $\mathrm{Pb}$, which were ranked in the seventh and second place in the priority list of dangerous substances published by the US Agency for Toxic Substances and Disease Registry (U.S. Public and Health Service, 1992). The data also indicated that almost all the metals in e-cigarette aerosols were less than one percent of the limit safety value except for $\mathrm{Ni}$, which was close to a quarter of the limit in ECM aerosol and could be mainly from the metallic coil in heating element (Table 3).

The potential cytotoxicity evaluation of TPM extracts of two e-cigarette aerosols and CS on cell levels also exhibited the significant differences. As shown in Fig. 1, the mild cytotoxicity could be found in the two e-cigarette groups at dose of 100 $\mu \mathrm{g} / \mathrm{mL}$, which were significantly weaker compared to CS. The effect of the TPM extracts on cell colony formation also certified that the CS exhibited intense inhibition on the four cell lines (Fig. 2). What's more, the inhibition of the ECT and ECM on cell colony formation were also much weaker than CS at the same dose.

\section{Conclusion}

In summary, the exposure risks of HPHCs in e-cigarette aerosols are mainly associated with the e-liquid flavoring agents, carrier solvents existing as primary ingredients or as products of thermal degradation, and the metals from the metallic coil in heating element. Thus, how to reduce their concentrations in aerosols is both a challenge and an innovation. The comparison of HPHCs in e-cigarette aerosols and CS, and their potential cytotoxicity on cell levels gives the further support to that the tested ecigarettes may represent a safer alternative to conventional cigarettes. What's more, the ingredients in e-cigarette aerosols with different flavor and battery output voltage are taking the obvious discrepancies, and the categories of ingredients in e-cigarette aerosols and CS are also possessing some differences, indicating the potential influence of these new ingredients and discrepancies should be paid more attention, and the relevant national standards also need to be established as soon as possible.

\section{Declarations}

\section{Acknowledgments}


The authors are indebted to Mr. Wolfman Yasha Daniel for proof-reading of the manuscript.

\section{Author contributions}

Writing \& editing: ZHW; Formal analysis: XDL, QL, AL, and YLH; Biological assays: JX and TX; Conceptualization and review: JXT.

\section{Funding}

This research was funded by The Science Fund of RELX (No. RELX-2020-001), which was the sole source of funding of this project.

\section{Availability of data and materials}

The datasets used and/or analyzed during the current study are available from the corresponding author on reasonable request.

\section{Ethics approval and consent to participate}

The data mentioned in this research do not involve ethical issues.

\section{Consent for publication}

No individual is named in this study. Consent forms were signed by all participants

\section{Competing interests}

The authors declare no competing interests.

\section{References}

1. AFNOR. XP D90-300-3. Electronic cigarettes and e-liquids - Part 3: Requirements and test methods for emissions. 2016 July.

2. Benowitz NL, and Fraiman JB. Cardiovascular effects of electronic cigarettes [J]. Nature Reviews Cardiology, 2017, 14: 447-456.

3. Belushkin M, Djoko, DT, EspositoM, et al. Selected harmful and potentially harmful constituents levels in commercial ecigarettes [J]. Chemical Research in Toxicology, 2020, 33(2): 657-668.

4. Biondi-Zoccai, G, Sciarretta S, Bullen C, et al. Acute effects of heat-not-burn, electronic vaping, and traditional tobacco combustion cigarettes: the Sapienza university of Rome-vascular assessment of proatherosclerotic effects of smoking (SUR-VAPES) 2 randomized trial [J]. Journal of the American Heart Association, 2019, 8(6): e010455.

5. Buchanan ND, Grimmer JA, Tanwar V, et al. Cardiovascular risk of electronic cigarettes: a review of preclinical and clinical studies [J]. Cardiovascular Research, 2020, 116(1): 40-50

6. Bullen $\mathrm{C}$, Howe $\mathrm{C}$, Laugesen $\mathrm{M}$, et al. Electronic cigarettes for smoking cessation: a randomized controlled trial [J]. The Lancet, 2013, 382(9905): 1629-1637.

7. Caponnetto P, Polosa R, Russo C, et al. Successful smoking cessation with electronic cigarettes in smokers with a documented history of recurring relapses: a case series [J]. Journal of Medical Case Reports, 2011, 5: 585.

8. Cheng T. Chemical evaluation of electronic cigarettes [J]. Tobacco Control, 2014, 23 (maysuppl.): ii11-ii17.

9. CORESTA recommended method No. 81, 2015. Routine analytical machine for e-cigarette aerosol generation and collection-definitions and standard conditions [Internet]. Paris: CORESTA; 2015 June.

10. CORESTA recommended method No. 72, 2017. Determination of tobacco-specific nitrosamines in tobacco and tobacco products by LC-MS/MS [Internet]. Paris: CORESTA; 2017 July. 
11. CORESTA recommended method No. 70, 2018. Determination of selected volatile organic compounds in mainstream cigarette smoke by GC-MS [Internet]. Paris: CORESTA; 2018 February.

12. CORESTA recommended method No. 74, 2019. Determination of selected carbonyls in mainstream cigarette smoke by HPLC [Internet]. Paris: CORESTA; 2019 August.

13. Czekala L, Simms L, Stevenson M, et al. Toxicological comparison of cigarette smoke and e-cigarette aerosol using a 3D in vitro human respiratory model [J]. Regulatory Toxicology \& Pharmacology, 2019. 103: 314-324.

14. Deng X, Zhang J, Liu Y, et al. TNF-a regulates the proteolytic degradation of ST6Gal-1 and endothelial cell-cell junctions through upregulating expression of BACE1 [J]. Scientific Reports, 2017, 7: 40256.

15. Ding Y, Trommel J, Yan X, et al. Determination of 14 polycyclic aromatic hydrocarbons in mainstream smoke from domestic cigarettes [J]. Environmental Science \& Technology, 2005, 39(2): 471-478.

16. GB 5009.265-2016. PRC National Standards for Food safety: Determination of polycyclic aromatic hydrocarbons in foods [S]. 2016 June.

17. Goniewicz ML, Knysak J, Gawron M, et al. Levels of selected carcinogens and toxicants in vapour from electronic cigarettes [J]. Tobacco Control, 2014, 23: 133-139.

18. Humidah A, Jin PH, Jamila C, et al. Comparative study of the effects of cigarette smoke and electronic cigarettes on human gingival fibroblast proliferation, migration and apoptosis [J]. Food and Chemical Toxicology, 2018, 118: 390-398.

19. Ito S, Matsumura K, Ishimori K, et al. In vitro long-term repeated exposure and exposure switching of a novel tobacco vapor product in a human organotypic culture of bronchial epithelial cells [J]. Journal of Applied Toxicology, 2020, doi: 10.1002/jat.3982.

20. Kosmider L, Sobczak A, Fik M, et al. Carbonyl compounds in electronic cigarette vapors: effects of nicotine solvent and battery output voltage [J]. Nicotine \& Tobacco Research, 2014, 16(10): 1319-1326.

21. Li J, Chen L, Liu Q, et al. Buformin suppresses proliferation and invasion via AMPK/S6 pathway in cervical cancer and synergizes with paclitaxel [J]. 2018, 19(6): 507-517.

22. Marco E, and Grimalt JO. A rapid method for the chromatographic analysis of volatile organic compounds in exhaled breath of tobacco cigarette and electronic cigarette smokers [J]. Journal of Chromatography A, 2015 1410: 51-59.

23. Merecz-Sadowska, S, Sitarek P, Zielinska-Blizniewska H, et al. A summary of in vitro and in vivo studies evaluating the impact of e-cigarette exposure on living organisms and the environment [J]. International Journal of Molecular Sciences, 2020, 21(2): 652 .

24. Nicol J, Fraser R, Walker L, et al. Comprehensive chemical characterization of the aerosol emissions of a vaping product based on a new technology [J]. Chemical Research in Toxicology, 2020, 33(3): 789-799.

25. Nutt DJ, Phillips LD, Balfour D, et al. Estimating the Harms of Nicotine-Containing Products Using the MCDA Approach [J]. European Addiction Research, 2014, 20: 218-225.

26. Pablo O, Walter G, Stefan T, et al. Metal concentrations in e-cigarette liquid and aerosol samples: the contribution of metallic coils [J]. Environmental Health Perspectives, 2018, 126(02): 027010.

27. Public Health England. 2015. McNeill A, Brose LS, Calder R, et al. E-cigarettes: an evidence updates: a report commissioned by Public Health England.

28. Romagna G, Allifranchini E, Bocchietto E, et al. Cytotoxicity evaluation of electronic cigarette vapor extract on cultured mammalian fibroblasts (ClearStream-LIFE): comparison with tobacco cigarette smoke extract [J]. Inhalation Toxicology, 2013, 25(6): 354-361.

29. Royal College of Physicians. 2016. Nicotine without smoke: Tobacco harm reduction. London: RCP.

30. Stepanov I, Hecht SS, Ramakrishnan S, et al. Tobacco-specific nitrosamines in smokeless tobacco products marketed in India [J]. International Journal of Cancer, 2005, 116(1): 16-19.

31. U.S. Public and Health Service. Agency for Toxic Substances and Disease Registry (ATSDR) [M]. 1992.

32. Yu Z, Feng H, Sun $X$, et al. Bufalin suppresses hepatocarcinogenesis by targeting $\beta$-catenin/TCF signaling via cell cyclerelated kinase [J]. Scientific Reports, 2018, 8(1): 3891.

Page $11 / 13$ 
Figures

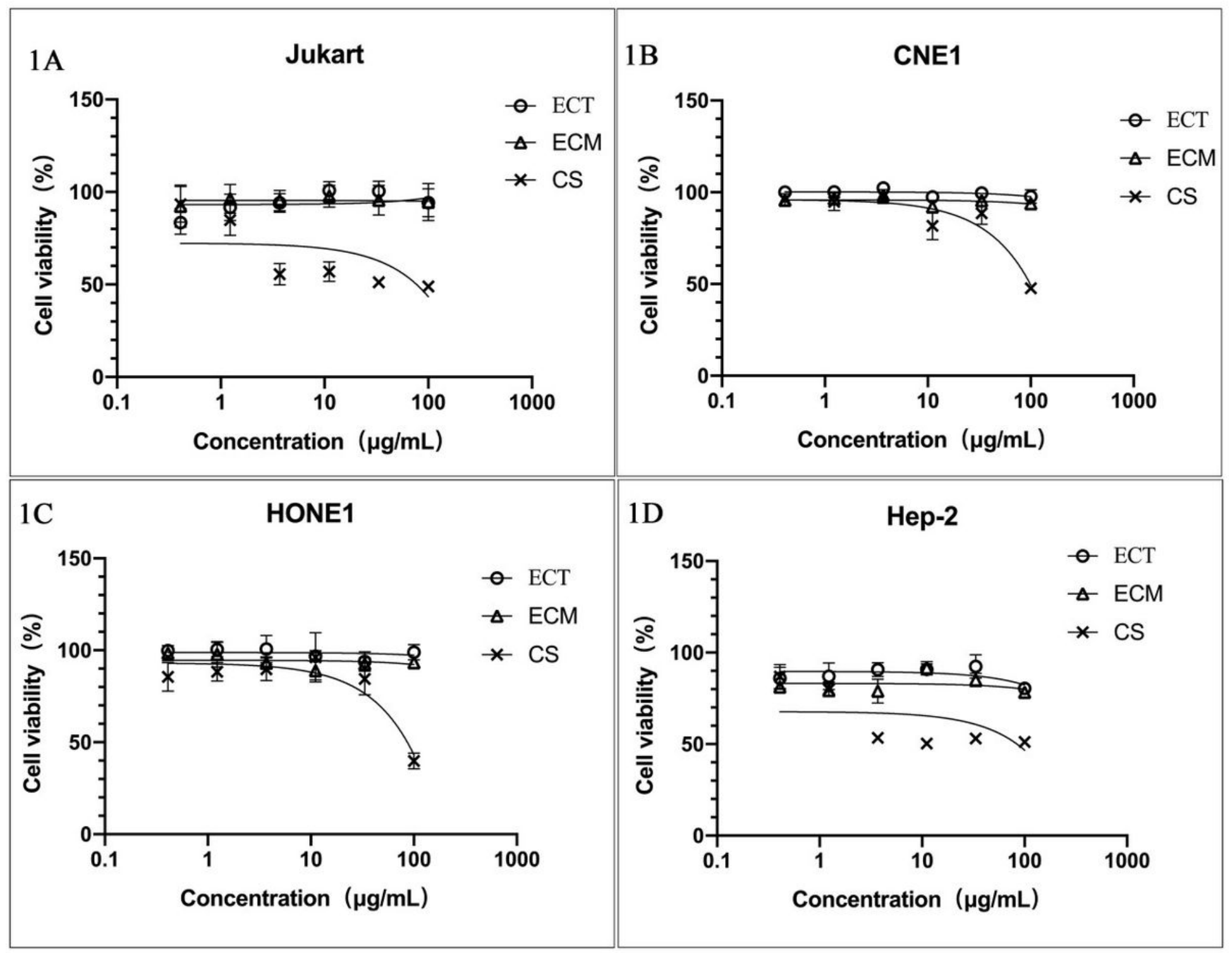

Figure 1

the cell viability of four cell lines in 48 hours after treat with the TPM extracts of ECM, ECT, and CS at gradient dose, $n=5$. 


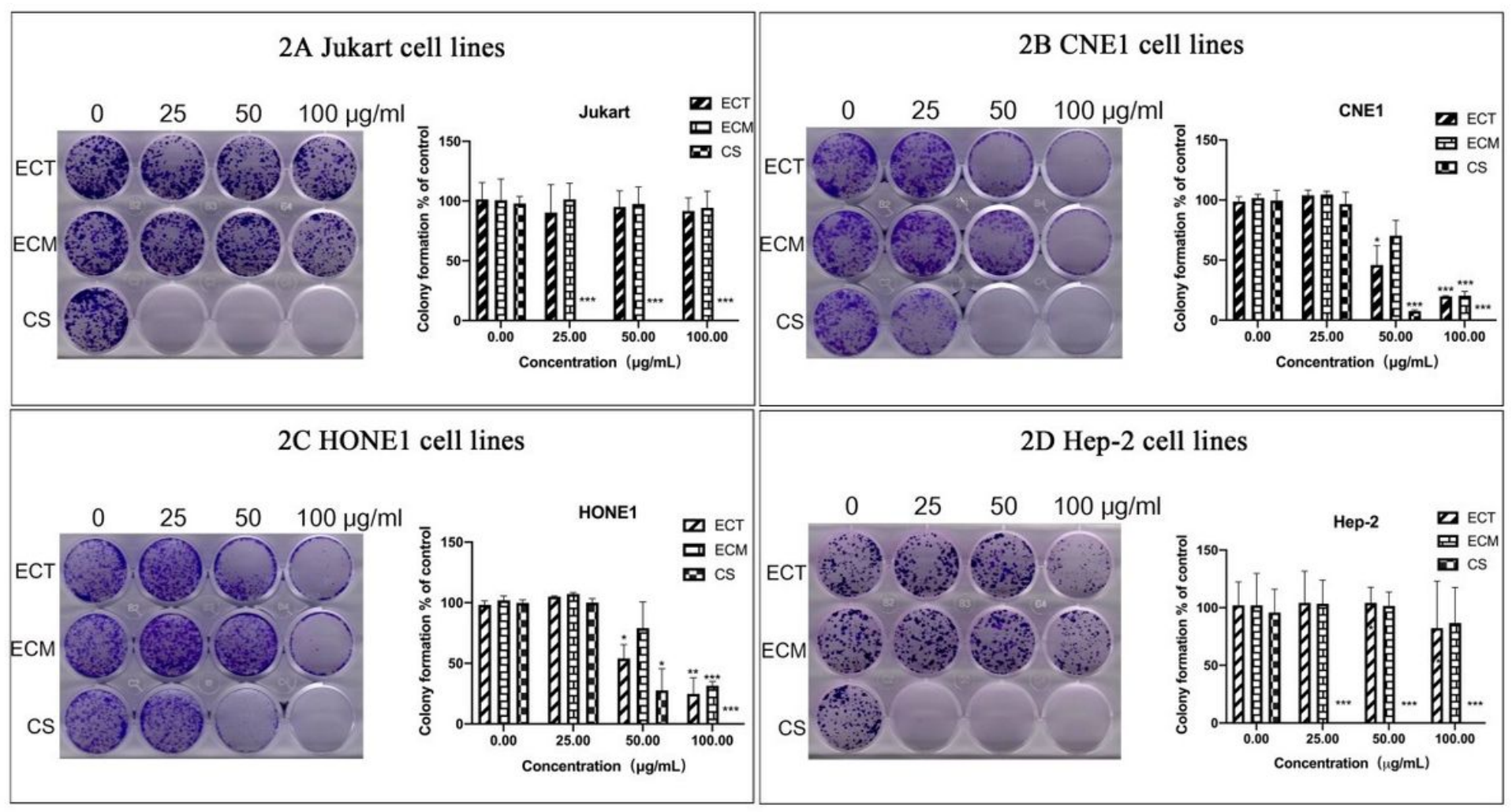

Figure 2

the inhibition effect of TPM extracts on the cell colony formation at gradient dose, ${ }^{\star} p<0.05, * \star p<0.01, * \star \star p<0.001, n=3$.

\section{Supplementary Files}

This is a list of supplementary files associated with this preprint. Click to download.

- 02SupplementaryMaterial.docx 